\title{
Do Repugnant Scents Increase Survival of Ground Nests? A Test with Artificial and Natural Duck Nests
}

\author{
VAnessa B. Harriman ${ }^{1,4}$, Justin A. PitT ${ }^{2}$, and Serge Larivière ${ }^{3}$ \\ ${ }^{1}$ Department of Biology, University of Saskatchewan, Saskatoon, Saskatchewan S7N 5E2 Canada \\ ${ }^{2}$ Department of Biological Sciences, University of Alberta, Edmonton, Alberta T6G 2E9 Canada \\ ${ }^{3}$ Cree Hunters and Trappers Income Security Board, Quebec, Quebec G1V 4K5 Canada \\ ${ }^{4}$ Corresponding author: vanessa.harriman@ec.gc.ca
}

Harriman, Vanessa B., Justin A. Pitt, and Serge Larivière. 2007. Do repugnant scents increase survival of ground nests? A test with artificial and natural duck nests. Canadian Field-Naturalist 121(2): 150-154.

Ground-nesting birds typically experience high predation rates on their nests, often by mammalian predators. As such, researchers and wildlife managers have employed numerous techniques to mitigate nest predation. We investigated the use of scents as repellents to deter predators from both artificial and natural ground nests. Survival rates of artificial nests did not differ among six groups of substances (Wald $\chi_{\mathrm{df}=5}^{2}=4.53, P<0.48$ ); however the chronology of predation among groups differed. A commercial Coyote urine based deterrent (DEER-D-TER ${ }^{\mathrm{TM}}$ ), human hair, and Worcestershire sauce were depredated faster than the control $\left(\mathrm{F}_{4,5}=40.3, P<0.001\right)$. Nest survival of natural nests differed among those groups tested (Wald $\chi_{\mathrm{df}}^{2}=2=11.8, P<0.005$ ); the eight mothball treatment decreased survival (Wald $\chi_{\mathrm{df}=1}^{2}=11.5, P<0.005$ ), which indicated that novel smells may attract predators or result in duck nest abandonment when coupled with natural duck scent. Chronologies of predation events among treatment groups were not different for natural nests $\left(\mathrm{F}_{2,3}=1.9, P=0.22\right)$. These findings indicate an interaction between novel scents and predator olfactory cues.

Key Words: Coyote, Canis latrans, urine, human hair, mothballs, napthaldehyde, nest predation, olfactory cues, waterfowl, Manitoba.

In the prairies of North America, predation on nests of ground-nesting ducks is considered the most important factor limiting waterfowl populations (Chafloun et al. 2002). As such, wildlife managers have developed and employed various techniques in an attempt to mitigate nest predation with varying degrees of success. Typically, a predation event by a mammalian predator such as the Striped Skunk (Mephitis mephitis), Red Fox (Vulpes vulpes), or Raccoon (Procyon lotor) is opportunistic (Larivière and Messier 1997). These predators are nocturnal and locate nests using audition (when the hen flushes) and olfaction (Larivière and Messier 1997). Although substances that may attract predators to nests have been investigated (Whelan et al. 1994; Clark and Wobeser 1997), scents that may repel predators from nests have yet to be tested.

Chemical compounds have been used successfully to repel animals, including mammals. Some animals have been effectively repelled by means of conditioned taste aversion (e.g., Hoover and Conover 1998) and through the use of noxious scents such as toxic compounds or odor from predatory animals (Sullivan et al. 1985; Rosell 2001).

We investigated the effectiveness of various scents to increase survival of duck nests in the Canadian prairies. Specifically, we tested whether applying DEER-DTER $^{\mathrm{TM}}$ (a commercial product containing Coyote (Canis latrans) urine), human hair, Worcestershire sauce, and mothball treatments could increase survival of eggs in artificial nests and the capability of DEERD-TER and mothball treatments to increase the sur- vival of eggs in natural duck nests. We also tested for differences in speed of predation events to determine whether specific scents may temporarily deter predators from a nest. Finally, we compared survival of eggs in artificial and natural nests.

\section{Study Area}

This study was conducted southeast of Minnedosa, Manitoba $\left(50^{\circ} 14^{\prime} 54^{\prime \prime N}, 99^{\circ} 50^{\prime} 30^{\prime \prime} \mathrm{W}\right)$, in an area supporting numerous small ( $<3$ ha) seasonal to permanent wetlands (ca. 14\% of study site) and characterized by intensive cultivation $(63 \%)$ of small grains (wheat, barley, and oats) and oil crops (canola and flax). Intermixed among agricultural fields are small aspen bluffs composed of poplar species (largely Quaking Aspen (Populus tremuloides) and Bur Oak (Quercus macrocarpa). The predator community is diverse and includes Raccoons, Striped Skunks, Coyotes (Canis latrans), Red Foxes, American Badgers (Taxidea taxus), and American Mink (Neovison vison). Predation of bird nests in the area is largely attributed to mammals (Pasitschniak-Arts and Messier 1995) but avian predation also occurs, primarily by birds such as the Common Raven (Corvus corax), American Crow (Corvus brachyrhynchos), and Black-billed Magpie (Pica pica).

\section{Methods}

The effectiveness of five groups of substances was compared to a control using artificial nests. The repellent substances were chosen based on unsubstantiated reports of their efficacy against mammals (human hair 


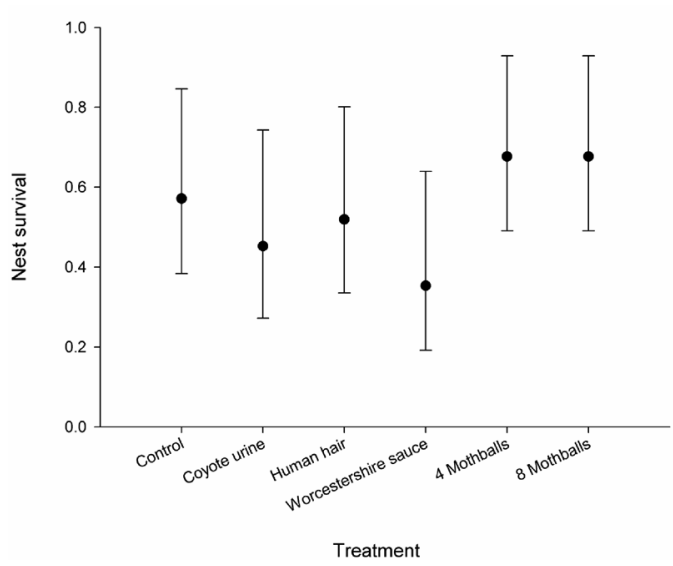

FIGURE 1. Daily nest survival (all eggs remaining in nest) of artificial duck nests treated with scents in Manitoba, 2002.

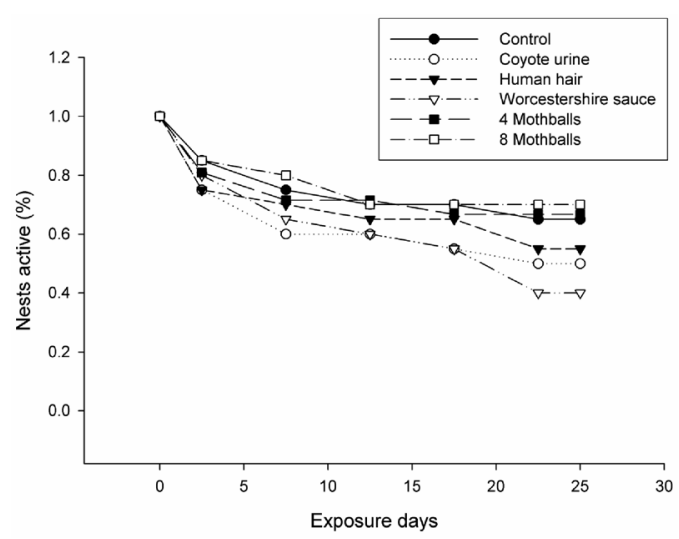

FIGURE 2. Percent of surviving artificial duck nests (all eggs remaining in nest) treated with scents at $\mathrm{X}$ exposure day in Manitoba, 2002.

and Worcestershire sauce) or from their commercial claims (DEER-D-TER ${ }^{\mathrm{TM}}$ and mothballs). Nests in the control group were each treated with $0.1 \mathrm{~L}$ of marsh water, which was poured along the outside edge of the nest. A packet of DEER-D-TER ${ }^{\mathrm{TM}}$ was placed on the outside edge of each nest of the second group. DEERD-TER ${ }^{\mathrm{TM}}$ consisted of a green plastic packet containing a mixture of sand and Coyote urine and was advertised to repel deer (Odocoileus spp.) and skunks. According to the manufacturer, this product was effective in the field for ca. 90 days. Group three received one cup of human hair which was collected from three different salons and was combined to create a homogeneous mixture. Group four received $0.15 \mathrm{~L}$ of Worcestershire sauce applied evenly to each egg and was reapplied on every subsequent visit. The fifth group

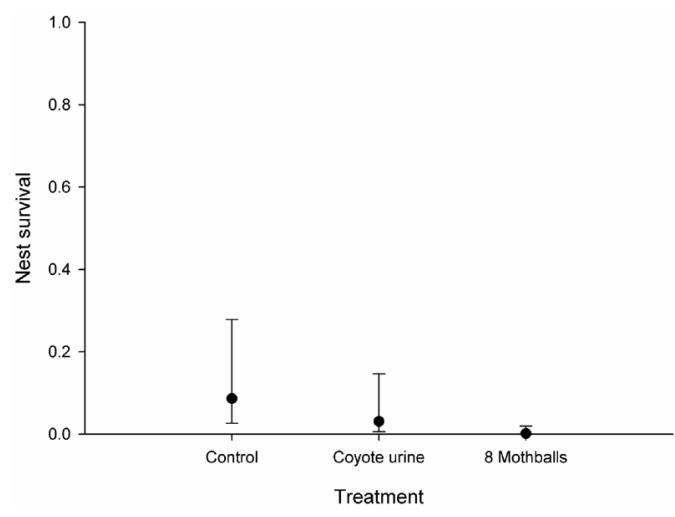

FIGURE 3. Daily nest survival (all eggs remaining in nest) of natural duck nests treated with scents in Manitoba, 2002.

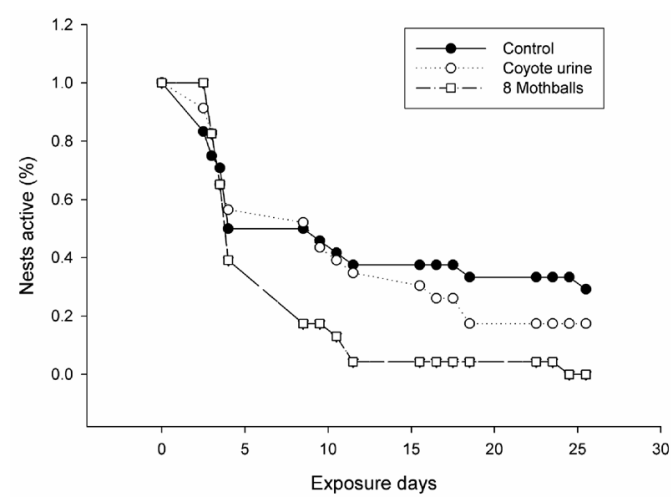

FIGURE 4. Percent of surviving natural duck nests (all eggs remaining in nest) treated with scents at $\mathrm{X}$ exposure day in Manitoba, 2002.

received four mothballs double wrapped in cheesecloth to prevent accidental ingestion by ducks or predators. The sixth group received eight mothballs, to determine if a greater amount yielded a different or stronger response, with two cheesecloth-wrapped groups of four mothballs placed on opposite sides of the outside edge of the nest. Three groups of substances were applied to natural nests: marsh water, DEER-D-TER ${ }^{\mathrm{TM}}$, and eight mothballs. Methodology and application of treatments for natural nests followed the same protocol as those of artificial nests.

Data were collected from 12 June to 7 July 2002. Artificial nests were created by depositing six mediumsized chicken eggs in a depression which was then covered with grass. Nests were marked by a thin welding rod at a distance of $1 \mathrm{~m}$. To avoid biases associated with 
habitat, all artificial nests were deployed in rights-ofway. Each nest was randomly placed within a $0.8 \mathrm{~km}$ stretch along four different, but intersecting, secondary unpaved grid roads. Artificial nests were located 300-1000 m apart on alternating sides of the road. Nests were placed in the densest vegetation as close as possible to the randomly selected location to reduce possible effects of concealment on survival. Artificial nests were visited every five days for 25 days and were approached from a different angle each visit to avoid the creation of a pathway to the nest. Rubber boots and latex gloves were worn at all times in hopes of concealing human scent. Each nest was randomly assigned one test substance until an equal number of nests per treatment was obtained.

Natural nests were located via the drag chain method. Only upland areas of dense nesting cover were searched and nests were marked with stakes placed $10 \mathrm{~m}$ away in a random direction. Nests were located on four separate quarter sections within 1.6-8.0 kilometers of each other. Each quarter section consisted of dense nesting cover and was bordered by either a crop or fallow land and a secondary gravel road.

Treatments of natural nests were assigned systematically because we were unaware of how many nests we would eventually locate and we sought to have a similar number of nests per treatment. If, on return to nests treated with mothballs, any of the mothballs had fallen out of the cheesecloth, the entire packet was replaced with a new one. Hens often incorporated the wrapped mothballs into their clutch and occasionally moved the packet(s) directly $(<0.5 \mathrm{~m})$ outside of the nest bowl. In these cases, the wrapped mothballs were left where the hen placed them. The first re-visit to the nest occurred between five and eight days after initial location and treatment application. Subsequent visits were made every seven days for up to a total of five visits depending on the fate of the nest. Natural nests were excluded from the analyses if they were abandoned but not depredated. However, we were unable to determine whether a nest had been abandoned and subsequently depredated.

All nests were deemed depredated (failed) after at least one of the eggs was removed from or destroyed in the nest. Mayfield logistic regression (Hazler 2004) was used to determine whether the nest survival of each treatment group differed from the nest survival of control nests within each nest type (artificial or natural). Because nests were not visited daily the exact date of failure was unknown. The number of days a nest was active ("exposure days") was calculated differently depending on the fate of the nest. Exposure days of nests that hatched (or survived to the last day of the study in the case of artificial nests) was the number of days that nest was under observation. Exposure days of failed nests was the number of days the nest was known to be active plus the midpoint between the last check and the last known active day. Nests that fail early are less likely to be detected and the Mayfield logistic regression reduces this bias by incorporating exposure days. Also, because this is a logistic-regression analysis, covariates can be incorporated, allowing for easy analysis of experimental data (Hazler 2004). All artificial nests were deployed on the same day and nest dragging was completed within three days which minimized the potential impact of seasonality on the data. An analysis of variance with repeated measures was used with respect to nest survival as a function of exposure days to determine whether there was a difference in the chronology of predation events between treatments as time progressed. All post-hoc tests were conducted using an all-pair-wise comparison Tukey test. Survival of artificial and natural nests was compared using Mayfield logistic regression.

\section{Results}

Survival of eggs in artificial nests was higher than that of natural nests (Wald $\chi_{\mathrm{df}=1}^{2}=43.4, P<0.001$ ). Artificial nest daily survival was 0.54 (SE \pm 0.003$)$ for all substances combined, while daily nest survival for natural nests was $0.04(\mathrm{SE} \pm 0.01)$ for all substances combined.

We deployed 120 artificial nests, with each treatment group containing 20 nests. Due to flooding, seven artificial nests were lost at various phases of the experiment and were excluded from further analyses. We found no significant difference in artificial nest survival rates among treatment groups (Wald $\chi_{\mathrm{df}=5}^{2}=4.5$, $P=0.48$; Figure 1).

For all treatments combined, there was a positive correlation between survival of artificial nests and exposure days, with survivorship of nests increasing with time $\left(\mathrm{F}_{4,25}=6.77, P<0.001\right)$ and the first five exposure days being the most fatal (Figure 2). Additionally, the chronology of predation differed among groups $\left(\mathrm{F}_{4,5}=40.3, P<0.001\right)$. Artificial nests containing both four and eight mothball treatments were depredated similarly to control nests $(\mathrm{q}=1.63, \mathrm{p}=6$, $P>0.05 ; \mathrm{q}=1.40, \mathrm{p}=6, P>0.05)$. However, nests treated with DEER-D-TER ${ }^{\mathrm{TM}}(\mathrm{q}=9.14, \mathrm{p}=6, P<0.05)$, human hair $(\mathrm{q}=4.84, \mathrm{p}=6, P<0.05)$, and Worcestershire sauce $(\mathrm{q}=13.9, \mathrm{p}=6, P<0.05)$ were depredated more quickly than control nests.

In total, 70 natural duck nests were located, with 24 receiving the control, 23 treated with DEER-D-TER ${ }^{\mathrm{TM}}$, and 23 treated with eight mothballs. Natural nest survival of the treatment groups differed from that of the control (Wald $\chi_{\text {df }=2}^{2}=11.82, P<0.005$; Figure 3) with survivorship of nests treated with eight mothballs being significantly lower (Wald $\chi_{\mathrm{df}=1}^{2}=11.47$, $P<0.005)$.

Nest survival did not vary as a function of exposure days for all natural duck nests combined $\left(\mathrm{F}_{3,8}=2.14\right.$, $P=0.17)$ despite a notably rapid decrease in nest sur- 
vival during the first five exposure days (Figure 4). Nest survival did not vary as a function of exposure days among treatments for natural duck nests $\left(\mathrm{F}_{3,8}=1.99\right.$, $P=0.22)$.

\section{Discussion}

We assessed the effect of various scent treatments on the survivorship of artificial and natural duck nests in the prairie pothole region of Canada. The application of scents did not increase nest survival of artificial or natural nests. Addition of mothballs decreased survival of natural nests. These results not only indicate that DEER-D-TER ${ }^{\mathrm{TM}}$, human hair, Worcestershire sauce, and mothballs were ineffective at repelling predators, but that certain scents may actually attract predators and/or increase duck nest abandonment rates.

The chronology of predation differed among treatments for artificial nests but not for natural nests. Contrary to expectations, artificial nests treated with DEERD-TER ${ }^{\mathrm{TM}}$, human hair, and Worcestershire sauce were depredated more quickly than control nests. Again these results may indicate a neophilic predator response. In particular, human-associated scents (i.e., hair and food items) may elicit predator attraction depending on the study site and the animal's experience with people. Although this study took place in a rural location, it is plausible that local predators may have positive associations with human dwellings and food, especially opportunistic species such as Striped Skunks and Raccoons (Pitt et al. 2008). Raccoons in particular often rely on anthropogenic foods at the northern edge of their range distribution (Larivière 2004; Pitt et al. 2008). Additionally, DEER-D-TER ${ }^{\mathrm{TM}}$ may have also attracted predators to nests, especially con-specifics. Mothballs and hair regularly went undisturbed at depredated nest sites whereas urine packets were often chewed on and/or ripped open.

The result of predators exhibiting neophilic tendencies may have important implications for waterfowl due to the propensity for which they are studied. The concealment of human scent should be an important consideration for researchers. Neophilic predators may increase their search radius when a particular scent cue is present (Whelan et al. 1994), possibly rendering human-visited nests more susceptible to predation.

Our study indicates that the survival rates of artificial and natural duck nests in the prairie pothole region are different and this may indicate that these nests are viewed differently from the perspective of a predator. Artificial nests realized higher survival rates compared to natural nests, which has been previously documented (Guyn and Clark 1997). The disproportionate difference in survival between artificial and natural nests could also in part be attributed to the presence of scents associated with natural nests, as well as the presence of a hen and the ability to cue in on the nest after a flush event (Larivière and Messier 1997). Alternatively, the observed difference may have been mediated by uncontrolled factors affecting natural nest survival, such as nest abandonment, hen species and behavior, nest concealment, and variation in nest spacing. Specifically, the eight mothball treatment may have provoked abandonment by nesting female ducks as some ejected mothballs from nests.

Conditioned taste aversion has been effective in deterring predators from nests (Nicolaus 1986; Conover 1990). Napthaldehyde (the noxious substance in mothballs) has been found to be effective in causing adverse responses by Coyotes when ingested (Hoover and Conover 1998). After repeated exposure, Coyotes avoided eggs injected with napthaldehyde. Although highly successful, it is expensive and time consuming to set up nests with injected chemicals. For future studies, it may be equally effective and less time consuming to combine the use of conditioned taste aversion with scents. Our results indicate that applied by themselves, these scents do not increase survival of either artificial or natural duck nests.

\section{Acknowledgments}

Delta Waterfowl Foundation provided funding and assistance for this study. Ducks Unlimited Canada kindly granted permission to search nesting cover. D. Coulton, H. Remenda, J. Estrella provided assistance in the field. Two reviews contributed to the clarity of the manuscript. This research was approved and conducted under Manitoba Wildlife Animal Care Committee \#2002-10. SL was supported through a National Science and Engineering Research Council discovery grant.

\section{Literature Cited}

Chafloun, A. D., F. R. Thompson, and M. J. Ratnaswamy. 2002. Nest predators and fragmentation: a review and meta-analysis. Conservation Biology 16: 306-318.

Clark, R. G., and B. K. Wobeser. 1997. Making sense of scents: effects of odour on survival of simulated duck nests. Journal of Avian Biology 28: 31-37.

Conover, M. R. 1990. Reducing mammalian predation on eggs by using a conditioned taste aversion to deceive predators. Journal of Wildlife Management 54: 360-365.

Guyn, K. L., and R. G. Clark. 1997. Cover characteristics and success of natural and artificial duck nests. Journal of Field Ornithology 68: 33-41.

Hazler, K. R. 2004. Mayfield logistic regression: a practical approach for analysis of nest survival. Auk 121: 707-716.

Hoover, S. E., and M. R. Conover. 1998. Effectiveness of volatile irritants at reducing consumption of eggs by captive coyotes. Journal of Wildlife Management 62: 399-405.

Larivière, S. 2004. Range expansion of raccoons in the Canadian prairies. Wildlife Society Bulletin 32: 955-963.

Larivière, S., and F. Messier. 1997. Characteristics of waterfowl nest depredation by the striped skunk: can predators be identified from nest remains? American Midland Naturalist 137: 393-396.

Nicolaus, L. K. 1986. Conditioned aversions in guild of egg predators: implications for aposematism and prey defence mimicry. American Midland Naturalist 117: 405-419. 
Pasitschniak-Arts, M., and F. Messier. 1995. Risk of predation on waterfowl nests in the Canadian Prairies: effects of habitat edges and agricultural practices. Oikos 73: 347-355.

Pitt, J. A., S. Larivière, and F. Messier. 2008. Survival and body condition of raccoons at the edge of their range. Journal of Wildlife Management 72: 389-395.

Rosell, F. 2001. Effectiveness of predator odours as gray squirrel repellents. Canadian Journal of Zoology 79: 1719-1723.
Sullivan, T. P., L. O. Nordstrom, and D. S. Sullivan. 1985. Use of predator odors as repellents to reduce feeding damage by herbivores II. Black-tailed deer (Odocoileus hemionus columbianus). Journal of Chemical Ecology 11: 921-935.

Whelan, C. J., M. L. Dilger, D. Robson, N. Hallyn, and S. Dilger. 1994. Effects of olfactory cues on artificial-nest experiments. Auk 111: 945-952.

Received 8 May 2006

Accepted 11 April 2008 